\title{
Health information politics: \\ Reconsidering the democratic ideal \\ of the Web as a source of medical knowledge \\ by Astrid Mager
}

\begin{abstract}
This paper challenges the democratic ideal of the Web as a new public sphere in the medical context. Drawing on a mix of methods it investigates how different Web site providers configure and position their diabetes sites in the multitude of online health information, search engine results in particular. Building on insights gained from critical new media studies and medical sociology, it shows that a range of power relations and information politics are involved in these practices, triggering information visibility hierarchies and a commercialisation of online health information, partly overlapping with off-line contexts. To conclude, it argues for reconsidering the democratic ideal of the Web and focusing on market dynamics involved in the production of medical Web information co-produced by Web site providers and search engine algorithms.
\end{abstract}

\section{Contents}

$\underline{\text { Introduction }}$

Constraints on the Web as a public sphere

$\underline{\text { Information politics }}$

$\underline{\text { Research questions }}$

$\underline{\text { Study and methods }}$

$\underline{\text { Research results }}$

Discussion and conclusion

\section{Introduction}

The imagination of the Web as a new or "better public sphere" (Gerhards and Schäfer, 2010) has been increasingly questioned in the past few years. The vision of the Web as a participatory medium has been challenged especially. Building on this line of work, this paper attempts to de-construct the democratic ideal of the Web in the medical context. In line with critical new media and Internet health studies (Nettleton, et al., 2005; Seale, 2005; Oudshoorn and Somers, 2006), I show that the Web, and social practices surrounding it, trigger 
information hierarchies partly overlapping with traditional power relations. Concretely, I focus on the production of Web information about diabetes, on Web site providers' strategies of configuring and positioning their sites in the multitude of online health information, and the role search engines play in their practices.

I begin with discussing limitations on the Web as a public sphere, focusing on the Web as a source of medical and health-related knowledge. I describe my research questions and empirical case study on the production of different diabetes-related Web sites conducted in Austria. Drawing on a heterogeneous body of data - hyperlink network maps, Web site analyses and qualitative interviews with Web site providers - I elaborate that not all types of Web site providers have the same technical abilities and resources to provide, format and position their diabetes-related sites in the mass of medical content available on the Web. Hence, not all types of actors manage to gain an equal voice in the concert of online health information. Rather, actors better adapted to the technology and its technical specificities search engines in particular - succeed in gaining a louder voice than smaller, less wellconnected sites. To conclude, I argue that the focus of attention should be shifted from the democratic ideal of the Web towards "information politics" (Rogers, 2004) and market dynamics involved in the production and distribution of medical Web information. Only then may the Web as a health information source be seriously discussed.

\section{Constraints on the Web as a public sphere}

Critical contributions from the field of critical new media studies and medical sociology have raised a number of limitations on the Web as a new public sphere and the democratic ideal surrounding it. First, the percentage of users actively contributing content is still very low, despite the fact that more people have access to the Internet. This particularly applies to the medical field, where only 10 percent of patients using the Web for medical purposes actively add content by posting information in an online discussion, listserv or other patient group forum, not to speak of developing a Web site, as a recent U.S. study has shown (Fox and Jones, 2009). Hence, the discourse is still dominated by a few. Having analyzed how patient organizations construct their Web sites, Oudshoorn and Somers (2006) have further shown that sites with limited budget and work force, such as NGOs, face constraints that have negative consequences on the realisation of original plans for the sites, such as implementing interactive elements. Oudshoorn and Somers have concluded that the analysis of the way patient-oriented Web sites are set up and designed helps to "understand the constraints and challenges of realising the democratic potentials of the Internet" [1] in the sense of giving an equal voice to different types of actors.

Second, the Web and the sociotechnical relations constituting it contribute to information hierarchies threatening the notion of a democratic exchange of ideas and opinions. Having investigated how information on human genome research is presented and structured in mass media discourses and search engine results, Gerhards and Schäfer (2010) challenged the notion of the Web as a "better public sphere". On the contrary, they have shown that especially search engines "might actually silence societal debate by giving more space to established actors and institutions, to experts and to expert evaluations and views, thereby replicating pre-existing power structures online." [2] Similar results have been found in the context of medical conditions. Having analysed how the issues of breast and prostate cancer 
are represented online, Seale (2005) refers to barriers that medical Web sites experience in gaining visibility. Net-savvy mainstream sites, such as major cancer charities, better succeed in gaining presence in search engine rankings, arguably at the expense of counter-cultural voices, according to Seale. Nettleton, et al. (2005) have also found that the first 20 Google results on eczema, asthma, and diabetes are dominated by Web sites from charities, medical institutions, and pharmaceutical companies, concluding that conventional institutions and medical material have become foregrounded on the Web [3]. Nettleton, et al. (2005) have thus argued that

"there has been a convergence in content between the 'old' and 'new' media that is undercutting earlier celebrations and concerns about the Internet as a medium that promotes a complex diversity of perspectives on health and illness." [4]

Consequently, Nettleton, et al. have stated that more research is needed to explore the underlying dynamics and mechanisms involved in the production and distribution of online health information.

Finally, the increasing commercialisation of the Web is seen as a threat to the democratic ideal of the Web (Spinelli, 2000; Papacharissi, 2002; Pickard, 2008; Fuchs, 2011). Papacharassi [5] clearly points out that "advertising revenue has more impact on programming than democratic ideals". The fact that personalized advertising has become the core of contemporary Internet businesses - most importantly Google - has triggered effects of the commodification of information and user data (Van Couvering, 2008). Based on Marxian thinking, Fuchs (2011) has clearly shown that large Internet companies create profit by exploiting users' data and content they produce by selling it to advertising clients. Having compared discourses around the democratic ideal of the Web and the radio, Spinelli [6] concluded "the word 'democracy' becomes a consumption-based parody of what might have been the medium's actual democratic potential". If and how the increasing commodification of the Web influences the production and distribution of medical Web sites - most particularly commercial ones financed by advertising — is understudied so far.

\section{Information politics}

Traditional medical institutions can be seen as foregrounded in search engine results at the expense of marginalised voices, according to the studies mentioned earlier. To better understand how these effects are created, I discuss various "information politics" (Rogers, 2004) involved in the delivery of Web information and the role technology plays therein. For the purpose of my analysis, I particularly focus on linking strategies and search engine politics.

Network theorists have convincingly argued that the Web space is not equally distributed, but rather made up of big, well-connected hubs and weakly connected, marginalised Web sites (Barabási, 2003; Rogers and Marres, 2000; Park and Thelwall, 2006). Consequently, a number of researchers have started to map and analyse these link networks. Rogers and Marres (2000), for example, have investigated link networks as issue networks. They have 
conceptualised links as recommendations of Web resources in a specific thematic field, which, taken together, constitute thematic networks. Besides thematically linking to relevant issues, Webmasters link to important actors and organisations, recognising them as meaningful participants in the debate. In this interpretation, groups of links may be read as social networks, as Park and Thelwall (2006) have similarly shown in their study on link networks in the academic field. In both cases, linking means to recognise. Non-linking, on the contrary, is a "sign of non-recognition, or, more radically, is an act of silencing through inaction." [7] Further, different types of Webmasters follow different linking strategies or "linking styles" (Rogers and Marres, 2000).

In regard to search engines, Google in particular, link practices fulfil yet another important task. According to its developers, Brin and Page (1998), Google's PageRank algorithm uses the number and quality of links a Web site earns as an indicator of the value of that site. A hyperlink from a site rated as important counts more than a hyperlink from an unimportant site. In this interpretation hyperlinks are seen as votes for a Web site, in a way that resembles the concept of recognition or citation (Brin and Page, 1998). While Google claims to use "the collective intelligence of the Web to determine a page's importance", a number of researchers have criticised its algorithm (Introna and Nissenbaum, 2000; Hindman, et al., 2003; Elmer, 2006; Rogers, 2009a). They have argued that the PageRank algorithm produces a content bias. In systematically giving prominence to larger, well-connected Web sites at the expense of smaller ones, search engines run counter to the democratic ideal of the Web, according to Introna and Nissenbaum (2000). Diaz (2008) has further discussed the self-perpetuating effects this triggers, recalling Merton's (1968) Matthew effect, which demonstrates that wellcited scholarly papers gain more citations over time:

"The problem is this: a well-linked page appears predominantly on search engines like Google; this page therefore enjoys greater traffic; and, as users become even more aware of the site, they link to it on their own pages, increasing the document's PageRank and visibility even further." []]

As users mainly go through search results from the top down and widely pick Web sites appearing as the first results, search engines create competition amongst Web site providers to occupy one of the "top ten seats" (Introna and Nissenbaum, 2000). Röhle (2009) has argued that Webmasters game the ranking system to boost the position of their sites through search engine optimisation (SEO) strategies, especially those who need user traffic to satisfy their advertising partners. Besides other factors that have gained importance in the algorithm over the past years, links may still be seen as a central currency in the Web economy (Röhle, 2009). How these strategies play out in the medical context, and how they vary amongst different types of Web site providers will be elaborated in this paper.

\section{Research questions}

Building on these theoretical and empirical insights, I pose the following two major research questions: 
$R Q 1$ : How do different types of Web site providers

configure their diabetes-related sites and try to make

them visible in the multitude of online health

information?

Following Nettleton, et al. 's (2005) call for more research on the production and distribution of online health information, the first research question focuses on Web site providers' practices of technically building and designing diabetes sites, but also strategies of making them visible in the mass of online health information, particularly in search engine results. The sites chosen for the analysis are provided by very different types of actors including professional health portals, pharmaceutical companies, semi-commercial sites, non-profit organisations and institutions to cover the diversity of online health information commercial and non-commercial, expert and lay, professional and self-made, to name but a few of the different types of information available — as will be described in detail further in this paper.

$R Q 2$ : How do their off-line institutions, companies and overall goals, but also search engines and their way of functioning shape Web site providers' practices?

The second research question is concerned with the different identities and agendas of the institutions offering the Web sites chosen for the analysis; their status outside of the Internet, in the "off-line" world, as I call it. Some of the sites, such as non-profit organisations and institutions, have a pre-Web existence in the off-line world, while other sites, like health portals and diabetes information sites, have no pre-Web identity. Their businesses were only set up to provide a site on diabetes and other health-related information. The question thus is how their respective standing in the off-line world shape the way their sites are presented and positioned online, since "the off-line" and "the online" should not be seen as two separate spheres. Rather, the off-line and the online appear to be tightly intertwined, as will be seen in the paper. Further, it asks how search engines like Google, and their algorithms and ways of "software-sorting" (Graham, 2005), influence site providers' individual practices in terms of search engine optimization (SEO) strategies, for example.

The description of the empirical analysis will be organized along the two research questions and hence presented in two separate sections. Before discussing the results, though, I describe the methods employed in this study.

\section{Study and methods}

To answer the research questions I draw on multiple types of data, which have been developed in the Austrian research project "Virtually Informed: The Internet in the Medical Field" (2005-2009). Web site providers' strategies of configuring and positioning their sites are difficult to observe directly. We thus employed a trio of methods to draw conclusions about the ways different types of site providers assemble their sites and try to gain visibility online. We developed (1) hyperlink network maps to gain a bird's eye perspective on the landscape of diabetes Web information; we analysed (2) different types of sites offering 
information on diabetes; and, finally conducted (3) qualitative interviews with representatives from these diabetes-related sites, as I exemplify in the following.

1. Drawing on work from the field of hyperlink research discussed earlier, we started mapping the health information landscape with the software IssueCrawler. IssueCrawler performs a co-link analysis to map densely interlinked communities of Web sites, which means it performs two steps of "exclusion" []. Consequently, not all linked sites are visualized, but only those sites that earn a link from at least two of the original starting points. The interrelations between these "survivors" are finally displayed as a network with Web sites as nodes and hyperlinks as links between them.

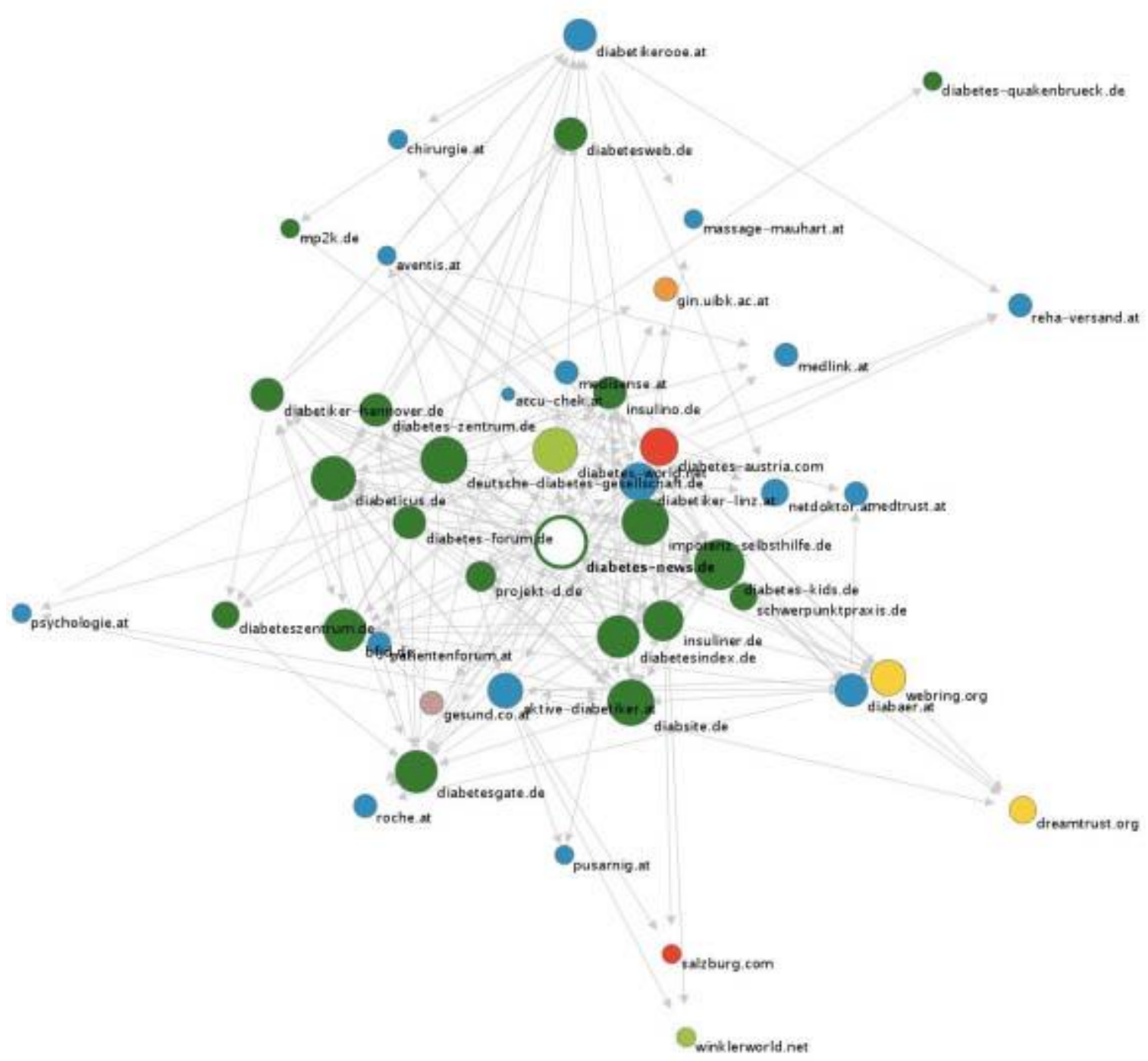

Figure 1: IssueCrawler network map displaying diabetes-related Web sites. The color of the nodes shows the domain of the sites, the size of the nodes indicates the number of links a site earns from the network, with the arrows explaining the direction of links. 
Hyperlink network maps, such as the one above, immediately show that diabetes-related sites are not equally distributed on the Web. Rather, certain Web sites are heavily interlinked nodes, while others are weakly connected, triggering consequences in terms of visibility. Linking politics may thus be seen as challenging the democratic ideal of giving an equal voice to all actors. How these link networks actually come into being, what ideas site providers inscribe in their link connections, and what consequences to visibility these linking politics trigger will be discussed later in this paper.

2. First impressions of linking practices formed from hyperlink networks were deepened through content analyses of five diabetes-related Web sites. All sites were chosen because they held a more or less dominant position in hyperlink network maps and search engine results. To cover the diversity of diabetesrelated sites in the Austrian context, these sites included a diabetes self-help group, a general practitioner specializing in diabetes, a general health portal, and a pharmaceutical company producing insulin and medical devices for diabetics. Finally, a semi-commercial site was selected, which was provided by a journalist afflicted by diabetes, who decided to share diabetes information (and advertising) from the perspective of a concerned person. The latter site indicates that the boundaries between commercial and non-commercial content tends to blur online. All sites were operated by Austrian providers and ranged from static HTML sites to more flexible database-driven sites. The language of the sites was German and their appearance evoked the charm of classical Web 1.0 sites, rather than more dynamic Web 2.0 offerings such as blogs and wikis. The five sites were qualitatively analysed according to the information provided on the different sites; how the information was structured and designed; how site providers presented themselves, whether images, interactive elements, and other features were displayed; how much advertising was present; and, what links were assembled on each site.

3. In addition, qualitative interviews were conducted with the providers of these sites to gain insights into their motivations, agendas and strategies involved in practices of providing and positioning their sites. Altogether, six extensive interviews were carried out with representatives of these sites who played a dominant role in their development and maintenance. The six interviewees included the chairman and Web designer of a self-help group; a general practitioner; the journalist offering a semi-commercial diabetes site; the PR manager of the pharmaceutical company; and, the director of a commercial health portal. The providers were asked about the primary goals of their sites; how they designed and structured information; whether professional Webmasters were involved; how they interlinked their sites; and, how they tried to attract and entice users. Finally, the network maps were discussed with the site providers to get an idea of how they viewed their own positions in these hyperlink networks. Results of these interviews were then juxtaposed with insights gained from the network maps and Web site analyses.

The interview material was fully transcribed, analysed with the qualitative research software ATLAS.ti [10], and coded along the research questions inspired by a grounded theory approach (Glaser and Strauss, 1968). The hyperlink networks and Web sites were systematically analysed by identifying categories and patterns that allowed for comparing them with each other. 


\section{Research results}

$R Q 1$ : How different types of Web site providers configure their medical sites

When asked why their sites were originally built, all Web site providers articulated the rather general goal of informing and supporting patients. Drawing on the rhetoric of patient empowerment, all interview partners said that they wanted to enable patients to challenge medical professionals and better cope with diabetes, a health condition that requires a great deal of information - ranging from learning how to measure blood sugar, how many bread units to eat per day, how to inject insulin, and what kind of nutrition and sports positively contribute to the patient's health state. When looking at the interviewees' narratives more closely, however, more specific reasons why to run a diabetes-related site may be seen. In the following, I discuss three strategies of configuring diabetes-related sites tightly intertwined with the providers' goals of offering a site in the first place: Creating sites as a representation of their off-line services, configuring sites as an advertising platform, and designing sites as an informational product. These three categories should be understood as analytical distinctions and do not mutually exclude each other.

\section{Creating a representation of their off-line services}

Traditional medical figures, such as the diabetes patient association and the general practitioner specialising in diabetes, primarily explained that they configured their sites to extend their off-line services of patient support into the online environment. Consequently, they designed their sites as an authentic representation of their off-line personalities and institutions, also reflected in the language they used. While the doctor deliberately tried to translate her professional medical knowledge into a simple language, the patient association naturally offered experiential information in a language easily understood by patients. On the homepage, they introduced themselves with photos and descriptions of their basic agenda, philosophy, and the services they offer, though only to a limited extent in the case of the doctor, due to the advertising ban she had to respect as a medical professional [11]. From the homepage, the user was directed to several subsidiary pages offering information on diabetes and related therapies, on recent activities and news around the association/ practice, as well as on the team and other issues. The information architecture on these sites may best be described as following a linear, tree-like structure, providing information from the top down. The design was simple and light in both cases, so as not to offend their primary target group of elderly people with flashy colours and backgrounds, as the chairman of the diabetes association explained. The doctor additionally mentioned that the style and colours of her site strongly resembles her practice, since she designed the site and practice in parallel:

"And it was really co-developed. Well, the yellow of the homepage, the green, this grey-green that I consider really calming, they are on the wall in the room where I work." [12]

These remarks demonstrate that her Web site and off-line institution appeared tightly intertwined. Similarly, the self-help association took the logo and design of their print magazine and applied them to their Web site, again showing the close entanglement between online and off-line cultures. One reason for this tight relationship was that both the doctor, 
who just started her private practice, and the diabetes association designed and technically built their sites on their own to save money, as they stated in interviews. This may be seen as mirrored on their sites, which appeared simple and reduced in terms of Web design and menu navigation and lacked interactive elements, evoking a do-it-yourself charm. This recalls the study by Oudshoorn and Somers (2006), who similarly showed that patient organisations had to face constraints in terms of providing interactive elements and more elaborated Web site features due to financial barriers.

\section{Configuring an advertising platform}

The PR manager of the pharmaceutical company producing insulin and medical devices, on the contrary, straightforwardly said that the company primarily uses their Web site as an advertising platform. When asked why the company provides the site, she answered that the site serves as the company's business card in the online environment, a space where companies increasingly need to be present: "Well, it is not possible not to have it. I think to have no Web site at all would be extremely bad in terms of image". Accordingly, the site was configured to cultivate the company's image. Besides biomedical information on diabetes, the site provided a virtual tour of the company, professional images of insulin injection pens and other products, as well as recent news on diabetes. The design of the site appeared professional and expensive, because it had been created by a professional Web design agency as part of the international corporate group, as the interview partner explained. On the company's site, the logo and image of the company were very prominent, similar to off-line advertising or PR campaigns. In this context, the PR manager referred to the economic dimension of the Web:

\footnotetext{
"Well, the Internet, here we have to stick to the truth, it exists because it creates money. Google benefits, all the ones uploading banner ads benefit. All that would not work if there were not very much money involved. (...) Well, that is also the reality. I know few people who upload informative texts for charity reasons. Besides maybe the church, but even the church will probably put an appeal for money next to it."
}

According to her - and her role as PR and marketing agent for the company - commercial dynamics pervade all topical areas on the Web, including medical ones. Like the doctor, the pharmaceutical company was not allowed to explicitly advertise their drugs by name. However, text on the site mentioned groups of drugs and their substances, most particularly on their partner site primarily designed for patients; this text was written in a comprehensible language. On this partner site, hardly any information about the company providing the site could be found, apart from the copyright section. This is significant as it created the possibility of implicitly advertising new drugs without mentioning either the company or the brand of the drug, a common practice amongst pharmaceutical companies, according to the interviewee. This clearly shows that commercial dynamics deeply pervade online health information. Similarly, Web site providers profiting from their sites referred to the economic dimension of medical Web information.

\section{Designing an informational product}

The director of the general health portal and the journalist offering the semi-commercial diabetes site both said that they run their sites as a business, on a very different scale. The 
director of the health portal employed a number of people ranging from medical professionals, journalists, to technical staff, to assure the quality of the largely biomedical information communicated to patients. The journalist ran the portal together with his business partner, with whom he previously owned a PR agency, and aimed at offering experiential diabetes information from a patient perspective. The primary goal of these sites was to generate income by informing patients about diabetes and other health-related issues. Both site providers kept their sites and companies economically successful through funds generated by sponsoring contracts and advertising, "because to run this kind of portal is a cost-intensive business", as the director of the health portal remarked. Corresponding to their goals, these providers designed their sites as informational products. Having no pre-Internet health institution in the background, they only briefly presented themselves on their homepages with slogans. Instead, their homepages were filled with different features, such as teaser stories and snippets of longer text, images evoking a good feeling, and quizzes, movies, a forum where patients could exchange experiences, and advertising. Both sites may best be described as "infotainment". While the health portal can be seen as offering a high-quality informational product where content and advertising were strictly distinguished, according to its director, the site offered by the journalist resembled a tabloid, where content and commerce intermingled strongly. To both Web site providers, however, user traffic was very important since they financed their sites through advertising and aimed at making a profit, which requires sufficient traffic to the site. Besides content, the appearance, design, and navigation of their sites were considered as very important features to keep users satisfied. Hence, both the health portal and the journalist's site were created by a professional Web design agency, assuring that the sites were well designed, but also functional and easy to use. In the case of the health portal, next to the top-down menu, teaser stories and other hypertext elements were provided, enabling users to navigate through their sites in multi-directional ways.

This analysis shows that the different motivations and aims in providing a diabetes-related Web site, as well as financial motives and technical know-how, strongly shaped the ways in which diabetes information was structured, designed and formatted. Web site providers from non-profit institutions built and designed their sites in simple, straightforward ways within their small budgets. Web site providers from companies and media businesses, in contrast, designed their sites in a much more elaborated way with visual features, interactive parts such as patient forums, and more flexible navigation structures, thanks to in-house technical experience and financial resources. These differences demonstrate that off-line power relations and commercial dynamics have a crucial impact on the way Web site providers design their sites, but also position them in the online health information landscape, as I discuss in the next section.

$R Q 2:$ How off-line dynamics and search engines shape visibility strategies

When discussing practices of positioning their sites and making them visible to users, the interviewees mainly referred to three visibility strategies, again closely related to their different motivations: collaborative forms of networking, individual techniques of search engine optimisation, and observing users' behaviour.

\section{Collaborative forms of networking}

The diabetes association and doctor providing a non-commercial Web site mainly relied on collaborative networking strategies to position their sites and attract users. The first step to gain visibility, these providers said, was to contact Web site providers with whom they had 
social relations with and propose to connect their respective sites through hyperlinks. This way, each site would benefit from other linked sites, as users would be channelled from one site to another by hyperlinks. In this interpretation, links mirror social networks. Accordingly, the Webmaster of the diabetes self-help group immediately started to talk about the sites surrounding his own site when I showed him the network map illustrated as Figure 2.

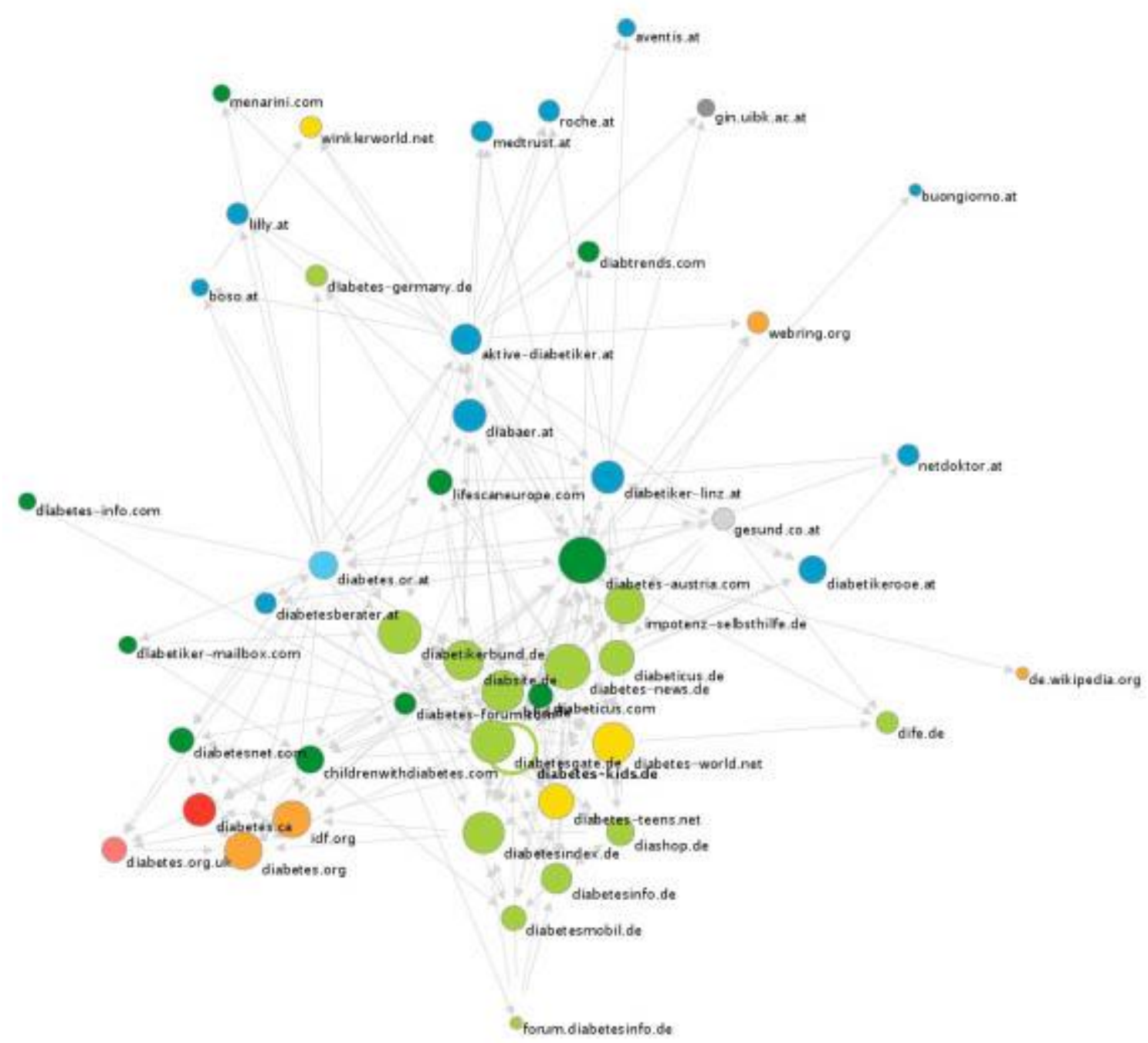

Figure 2: Network map displaying Austrian diabetes self-help sites heavily interlinked with German sites, created with the IssueCrawler in 2006.

According to the interviewee, the network primarily displays sites of institutions the self-help group collaborated with mirroring the lively diabetes self-help scene that developed in Austria (blue nodes on top of the image). Further, the network shows links from patient groups to pharmaceutical companies (nodes on the edge of the network on top), illustrating that companies financially support patient movements. Pharmaceutical companies, however, are not interlinked indicating a different linking, or rather non-linking, style, discussed later in this paper. Finally, Austrian self-help sites heavily interconnected their sites with German 
and international sites, primarily self-help sites (green and orange nodes at the bottom of the network). Hence, this hyperlink network appears to be what Rogers and Marres (2000) coined an "issue network".

In issue networks, links may be seen as recommendations to users. When asked whether he looked through the sites he linked to, the Web administrator of the self-help association answered, "Sure. (...) I do not want to somehow relate our empowered patients with, with something like charlatanism. That's something I reject. That's something I don't do." Like off-line networking, online networking implies not only helping each other but also denying support to other entities by excluding them from the network or "silencing them through inaction" (Rogers and Marres, 2000). While the self-help group excluded sites representing institutions they had trouble with, the director of the general health portal and the pharmaceutical company denied linking on general principles. Both Web site providers interpreted links to other sites as a way of losing users, especially when making link exchanges with smaller sites having fewer "unique clients", as the director of the health portal technically put it. This shows that collective strategies of gaining visibility end where competition starts. Link exchanges supposed to create mutual pathways between Web sites may turn into one-way streets when the size and traffic of sites differ too greatly, according to him. The visibility generated this way did not pay off relative to the number of users potentially lost. Further, losing users would also mean losing appeal to sponsors, threatening his business success. This underlines that the provider of the health portal perceived himself in a competitive relationship with other Web sites. Similarly, the PR manager of the pharmaceutical company did not link to other corporations in the field of diabetes, she said, mirroring off-line dynamics.

\section{Individual techniques of search engine optimisation}

While Web sites in competition with each other hardly employed links to gain visibility, they strongly employed individual techniques of search engine optimisation (SEO). In talking about the way users reached their sites, all Web site providers mentioned search engines rather than links. Providers of commercial sites, however, expressed a much stronger need to be present within the "top ten seats" (Introna and Nissenbaum, 2000) of search results. Hence, they articulated a quite elaborated understanding of Google's PageRank algorithm and a strong willingness to adapt their sites accordingly. The director of the health portal, for example, referred to the amount of links pointing to the site, keywords, and text as central elements co-determining the position of Web sites in organic search engine results (as opposed to paid links, which all site providers included in the study neglected). Extensive link exchanges with other sites may thus be seen as serving the goal of gaining visibility in search engine results as well, as the provider of the semi-commercial site argued. The provider of the health information portal, however, mainly invested funds to gain visibility in search engine results. When asked whether he cared about SEO strategies, the director of the health portal answered: "We do our homework, of course". To be able to maintain a professional health portal, it is obligatory to get technical support from professional SEO agencies, ranging from basic adjustments of links and metatext to sophisticated audience analysis, he explained. Similarly, the PR manager of the pharmaceutical company said that the technical side of the Web site was maintained by the headquarters of the corporation in a professional way. This indicates that for-profit medical sites gamed search engine algorithms on a large scale. Providers of non-profit Web sites, in contrast, associated the strategy of gaining visibility by deliberately trying to climb up the Google result list with manipulating their sites and off-line services that appeared tightly intermingled with their sites. When the Webmaster of the diabetes association was asked whether he cared about SEO, he said: 
“(...) and it isn't like we make a living from this, or our

business performance is dependent on how many

people look at it and buy from me, yes? We are a self-

help group, which (...) actually does not earn money,

and therefore we offer information, but we do not

impose it on anyone (laughs)."

He further added that putting extra links on the site to please Google would run counter to his basic approach to links as recommendations for users. This shows that there is a certain tension between serving users and serving search engines that for-profit Web sites are more willing to accept due to their primary goal of raising user traffic (and money).

\section{Observing users' behaviour}

Finally, some providers followed the strategy of extending their online presence by observing users. Besides anticipating users' keywords, a number of Web site providers electronically observed what search terms users employed to reach their sites. Both the PR manager of the pharmaceutical company and the doctor said that they use statistics like those generated by Google Analytics to figure out what search terms users chose to reach their sites and adapt their content accordingly. Providers offering medical Web sites to make a profit were particularly interested in the number of users coming to their sites. The diabetic offering the semi-commercial site proudly discussed the number of visitors and what parts of his site had generated the most visitors (a section he called "love and sex"). In addition to site statistics, the director of the health portal said that they conducted online surveys with their users on a regular basis. With this data, the director was able to estimate that the majority of the portal's users were women and to adapt the site to women's needs, for example. This also explains why professional sites tended to better correspond to users' needs. The director further added that he also tries to raise the number of users accessing the site via bookmarks because "the dependency on search engines is not that good".

None of the investigated Web sites made use of social media such as Facebook or Twitter at the time of our analysis. Since the initial study, both the professional health portal and the semi-commercial diabetes site have Facebook and Twitter buttons on their sites, indicating their desire to use social media to attract additional users. All of the other sites still do not use any of these services. This underlines once again that the two sites operated as businesses have the greatest motivation to increase user traffic, not the least to satisfy their advertising clients. How the use of Facebook, Twitter and co. will influence the distribution and visibility of certain types of health information remains to be seen in the future.

\section{Discussion and conclusion}

This paper investigated how different types of diabetes-related Web sites - ranging from professional to self-made pages, commercial to non-commercial information sources, expert to lay sites - are designed, formatted and positioned in the mass of online health information. In line with Oudshoorn and Somers (2006), it has shown that the different goals Web site providers follow, but also their resources in terms of technical expertise and budget have a crucial impact on the way their sites are configured and made available to users. The 
increasing dominance of search engines in user practices led to a battle for attention amongst Web site providers. All site providers examined in the study employed a variety of strategies to gain visibility in search engine results. Particularly large sites with sufficient manpower and technical know-how aggressively tried to climb up Google results, by trying to tweak the PageRank algorithm, rather than their users. With the omnipresence of Google, information politics and strategies of search engine optimisation, as noted in critical new media studies (such as Rogers, 2009a; Röhle, 2009), have entered the medical realm. Together with selfperpetuating effects that search engines trigger (Diaz 2008), this leads to centralising tendencies partly mirroring off-line power relations and hierarchies. Moreover, these tendencies leading to the commodification of medical Web information challenge the democratic ideal of the Web. Since the battle for attention is primarily fought and won by Web site providers of large, professional, and often commercial sites with significant budgets for elaborated SEO strategies, the "top ten seats" (Introna and Nissenbaum, 2000) are heavily dominated by big players, such as general health portals - not to speak of paid links, which additionally contribute to commercialisation tendencies of (diabetes-related) Web information.

These information hierarchies and biases, co-produced by Web site providers' practices as well as search algorithms like PageRank, have a crucial impact on the way users filter, select and ingest health information from the Web. Comparing the results presented in this paper with results from our analysis of users' search behaviour, also conducted in the larger project "Virtually Informed" [13] (see Mager, 2009; 2012a), illustrates how users' information acquisition is influenced by the way search engines rank their results. When employing general search terms such as "diabetes" or "type 2 diabetes", users primarily ended up on large, well-optimized Web sites, such as the general health portal analysed in this paper. Only when going further down search results or employing more specialised keywords will users reach smaller, non-profit sites, such as those by the patient association or the doctor [14]. Since large Web sites, such as those generated as general health portals or provided by pharmaceutical companies, primarily offered biomedical knowledge rather than experiential or alternative medical knowledge, these results support the "media convergence" thesis formulated by Seale (2005) and Nettleton, et al. (2005). They confirm the convergence between "old" media - and their tendency to privilege orthodox medical knowledge — and "new" media, undermining the celebrated diversity of perspectives on health and illness, as argued earlier. The Web should thus not be seen as entirely removed from the off-line environment. Rather, off-line power relations are translated into the online environment, strengthening large and popular medical institutions and viewpoints, while silencing actors with less prominent voices and counter-cultural approaches. These power relations can be seen as crucially contradicting the notion of the Web as a public sphere, populated by speakers with equal opportunities to reach a global audience.

Having focused on the production and distribution of diabetes-related Web sites, however, this paper suggests that we should not just blame Google as threatening notions of the democratic ideal for the Web. Rather, Google and the biases and "information politics" (Rogers, 2004) it triggers are also a result of the practices of both Web site providers and users. Hence, euphoric visions of the Web as a public sphere or a "democratic 'bottom-up' medium" (Anderson, et al., 2003) seem rather naïve, given the complex sociotechnical dynamics involved in the creation and distribution of medical Web information. I thus argue for reconsidering the democratic ideal of the Web and focusing on power relations and market dynamics, co-produced by Web site providers and search engine algorithms. Rather than a public sphere, the Web may be seen as a medical marketplace following rules of supply and demand present in contemporary capitalism. Search engines, like Google, incorporate a 
capitalist ideology in their algorithm and hence solidify a capitalist spirit in our mediasaturated society (Mager, 2012b). Web site providers' practices of strategically gaining visibility and elaborate SEO techniques contribute to knowledge hierarchies and commercial biases, reflecting off-line power relations. All of these sociotechnical dynamics heavily influence which voices are heard in the medical market place. We need to reach a better understanding of search engine politics and Web site strategies involved in the production of online health information. Only then can the democratic potential of the Web, and its constraints, be seriously discussed.

\section{About the author}

Astrid Mager works as a postdoctoral researcher at the Institute of Technology Assessment, Austrian Academy of the Sciences. She has a Ph.D. in philosophy from the Department of Social Studies of Science at the University of Vienna. Her dissertation, entitled "Mediated knowledge", is closely related to this paper. Her primary research interests include search engine politics, critical theory, market capitalism, privacy, Internet politics, digital methods and their implications.

E-mail: astrid [dot] mager [at] oeaw [dot] ac [dot] at

\section{Acknowledgements}

The research for this paper was developed in the project "Virtually Informed: The Internet in the Medical Field", carried out at the Department of Social Studies of Science, University of Vienna (2005-2009; funded by the Austrian Science Fund, P18006). I would like to thank Ulrike Felt (project leader), Lisa Gugglberger, Bernhard Höcher, Sonja Österreicher and Paul Ringler for having collaborated with me on the project, as well as our interview partners for having shared their opinions with us. I would further like to thank René König and my colleagues from HUMlab for their helpful comments on earlier drafts of this article. Finally, I am grateful to Patrik Svensson for the postdoctoral fellowship at the HUMlab, Umea University in Sweden, which provided me with the freedom to write this paper and to Mike Frangos for language editing.

\section{Notes}

1. Oudshoorn and Somers, 2006, p. 658.

2. Gerhards and Schäfer, 2010, p. 156.

3. Broom and Tovey (2008) have added that the choice of biomedical search terms that users employ may further contribute to a reinforcement of biomedicalization and a mechanistic conception of cancer in contrast to non-biomedical treatments.

4. Nettleton, et al., 2005, p. 976.

5. Papacharissi, 2002, p. 19. 
6. Spinelli, 2000, p. 268.

7. Rogers and Marres, 2000, p. 157.

8. Diaz, 2008, p. 17.

9. IssueCrawler has been developed by Govcom.org in Amsterdam; for further information, visit http://www.govcom.org/ (accessed August 2012). In addition to co-link analysis, other settings can be chosen, such as the inter-actor analysis, which analyses how the starting points are interrelated. For more information on the Issuecrawler, see also Rogers (2009b).

10. ATLAS.ti scientific software development GmbH, at http://www.atlas.com, accessed August 2012.

11. The advertising ban forbids medical professionals and pharmaceutical companies to advertise therapies, drugs or other medical products, according to Austrian regulations. A drug may be discussed by mentioning its ingredients, but not its specific brand.

12. All interviews were conducted in German; quotations translated by the author.

13. In these search experiments, 40 users varying in gender, age, educational background, Internet skills, and medical background were given a fictive scenario stating that they had just come from the doctor with a diagnosis of a chronic disease (10 participants got diabetes as a health condition). The participants were asked to use the Web to search for information relevant to them in this particular situation. The participants' online searches were saved with the software "My Screen Recorder", which captures desktop activity and stores it as a video file.

14. More recently, Wikipedia.org has succeeded in often occupying one of the top positions in Google's search results due to its large amount of text and number of links as well as the broad range of topics that it covers.

\section{References}

A.-L. Barabási, 2003. Linked: How everything is connected with everything else and what this means for business, science, and everyday life. New York: Plume.

S. Brin and L. Page, 1998. "The anatomy of a large-scale hypertextual Web search engine," Computer Networks and ISDN Systems, volume 30, numbers 1-7, pp. 107-117.

G. Elmer, 2006. "Re-tooling the network: Parsing the links and codes of the Web," Convergence, volume 12, number 1, pp. 9-19.

C. Fuchs, 2011. "A contribution to the critique of the political economy of Google," Fast Capitalism, volume 8, number 1, at http://www.uta.edu/huma/agger/fastcapitalism/8_1/fuchs8_1.html, accessed August 2012. 
J. Gerhards and M. Schäfer, 2010. "Is the Internet a better public sphere? Comparing old and new media in the USA and Germany," New Media \& Society, volume 12, number 1, pp. 143160.

B. Glaser and A. Strauss, 1968. The discovery of grounded theory: Strategies for qualitative research. London: Weidenfeld and Nicolson.

S. Graham, 2005. "Software-sorted geographies," Progress in Human Geography, volume 29, number 5, pp. 562-580.

M. Hindman, K. Tsioutsiouliklis and J. Johnson, 2003. “Googlearchy': How a few heavilylinked sites dominate politics online," paper presented at the annual meeting of the American Political Science Association; version at http://www.cs.princeton.edu/ kt/mpsa03.pdf, accessed September 2012.

L. Introna and H. Nissenbaum, 2000. "The public good vision of the Internet and the politics of search engines," In: R. Rogers (editor). Preferred placement: Knowledge politics on the Web. Maastricht: Jan van Eyck Editions, pp. 25-47.

A. Mager, 2012a "Search engines matter: From educating users towards engaging with online health information practices," Policy \& Internet, volume 4, number 2, at http://www.psocommons.org/policyandinternet/vol4/iss2/art7/, accessed September 2012.

A. Mager, 2012b "Algorithmic ideology: How capitalist society shapes search engines" Information, Communication \& Society, pp. 1-19.

A. Mager, 2009 "Mediated health: Sociotechnical practices of providing and using online health information," New Media \& Society, volume 11, number 7, pp. 1,123-1,142.

R. Merton, 1968. "The Matthew Effect in science," Science, volume 159, number 3810, pp. 56-63.

S. Nettleton, R. Burrows and L. O'Malley, 2005. "The mundane realities of the everyday lay use of the Internet for health, and their consequences for media convergence," Sociology of Health \& Illness, volume 27, number 7, pp. 972-992.

N. Oudshoorn and A. Somers, 2006. "Constructing the digital patient: Patient organizations and the development of health Web sites," Information, Communication \& Society, volume 9, number 5, pp. 657-675.

Z. Papacharissi, 2002. "The virtual sphere: The Internet as a public sphere," New Media \& Society, volume 4, number 1, pp. 9-27.

H. Park and M. Thelwall, 2006. "Web-science communication in the age of globalization," New Media \& Society, volume 8, number 4, pp. 629-650.

V. Pickard, 2008. "Cooptation and cooperation: Institutional exemplars of democratic Internet technology," New Media \& Society, volume 10, number 4, pp. 625-645. 
T. Röhle, 2009. "Dissecting the gatekeepers: Relational perspectives on the power of search engines," In: K. Becker and F. Stalder (editors). Deep search: The politics of search engines beyond Google. Innsbruck: Studien Verlag, pp. 117-132.

R. Rogers, 2009a. "The Googlization question, and the inculpable engine," In: K. Becker and F. Stalder (editors). Deep search: The politics of search engines beyond Google. Innsbruck: Studien Verlag, pp. 173-184.

R. Rogers, 2009b. The end of the virtual: Digital methods. Amsterdam: Vossiuspers UvA.

R. Rogers, 2004. Information politics on the Web. Cambridge, Mass.: MIT Press.

R. Rogers and N. Marres, 2000. "Landscaping climate change: A mapping technique for understanding science and technology debates on the World Wide Web," Public Understanding of Science, volume 9, number 2, pp. 141-163.

C. Seale, 2005. "New directions for critical Internet health studies: Representing cancer experience on the Web," Sociology of Health \& Illness, volume 27, number 4, pp. 515-540.

M. Spinelli, 2000. "Democratic rhetoric and emergent media: The marketing of participatory community on radio and the Internet," International Journal of Cultural Studies, volume 3, number 2, pp. 268-278.

E. Van Couvering, 2008. "The history of the Internet search engine: Navigational media and the traffic commodity," In: A. Spink and M. Zimmer (editors). Web search: Multidisciplinary perspectives. Berlin: Springer, pp. 177-206.

\section{Editorial history}

Received 19 December 2011; revised 24 August 2012; accepted 27 August 2012.

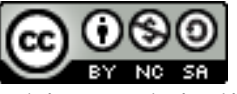

This work is licensed under a Creative Commons Attribution-NonCommercial-ShareAlike 3.0 Unported License.

Health information politics: Reconsidering the democratic ideal of the Web as a source of medical knowledge

by Astrid Mager

First Monday, Volume 17, Number 10 - 1 October 2012

http://journals.uic.edu/ojs/index.php/fm/article/viewArticle/3895/3318

doi:10.5210/fm.v17i10.3895 